| Original | Article |

\title{
Comparative efficacy of nanofilled and microfilled resin-modified glass ionomer as pits and fissure sealant in permanent molar teeth
}

\author{
Manzuma Akhter Zakaria, Mozammal Hossain and Md. Ali Asgor Moral
}

\begin{abstract}
Article Info
Department of Conservative Dentistry and Endodontics, Faculty of Dentistry, Bangabandhu Sheikh Mujib Medical University, Shahbag, Dhaka, Bangladesh

For Correspondence:

Mozammal Hossain

hossainresearch@hotmail.com

Received:

Accepted:

Available Online:

13 March 2017

2 April 2017

22 May 2017

ISSN: 2224-7750 (Online) 2074-2908 (Print)

DOI: 10.3329/bsmmuj.v10i2.31877

Cite this article:

Zakaria MA, Hossain M, Moral MAA.

Comparative efficacy of nanofilled and microfilled resin-modified glass ionomer as pits and fissure sealant in permanent molar teeth. Bangabandhu Sheikh Mujib Med Univ J. 2017; 10: 53-57.

Copyright:

The copyright of this article is retained by the author(s) [Attribution CC-BY 4.0]

Available at:

www.banglajol.info

A Journal of Bangabandhu Sheikh Mujib Medical University, Dhaka, Bangladesh

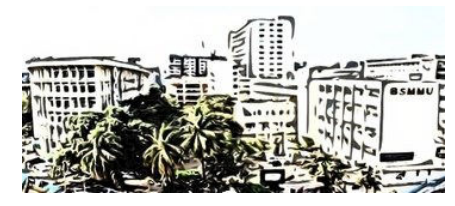

\section{Abstract}

\section{Introduction}

Occlusal surfaces of molar teeth are considered to be highly susceptible to caries development because of their morphological complexity (as fissure or pits and fissure) and plaque accumulation. Difficulties with brushing during tooth eruption and hypomineralization of Pits and Fissures in children and adolescents lead to early initiation and intensive progression of occlusal caries. While levels of tooth decay (dental caries) in children and adolescents have declined in many parts of the world in recent decades, caries, remain a public health problem in many countries. 1 Oral health data for children showed that $22 \%$ of 8 years old, over $50 \%$ of 12 years old and approximately $75 \%$ of 15 years old have experienced decay in their permanent teeth.2 Furthermore, the molar teeth account for most of the decay experience in primary, $\underline{3}$ and permanent teeth of almost all $97 \%$ of the decay in permanent teeth of 8 years old occurs in the first permanents molar, while the first and second molars together account for 85 and $79 \%$ of decay experienced by 12 and 15 years old, respectively. The molar teeth have many grooves (fissures) and pits on the chewing (occlusal) surface and on the buccal and palatal surface which can be very difficult to keep clean. These are two sites most susceptible to developing decay. $\underline{4}$
\end{abstract}

The purpose of the present study was to compare the efficacy of nanofilled and microfilled resinmodified glass ionomer as pits and fissure sealants in permanent molar teeth. Ninety six teeth having fissure at the occlusal surface were randomly divided into two groups: Group I: Treated by nanofilled resin-modified glass ionomer sealant and Group II: Treated by microfilled resinmodified glass ionomer sealants. Clinical assessment was performed by modified Ryge's criteria by means of retention, color match, marginal adaptation at 3, 6, and 12 months follow-up visit. Chi -square test was used for testing differences between the two groups; a value of $\mathrm{p}<0.05$ was considered as statistically significant. The results revealed that at 12 months observation period, nanofilled resin-modified glass ionomer sealant showed better retention, color stability and marginal adaptation than that of microfilled resin-modified glass ionomer sealants. Furthermore, the differences between two groups in respect to marginal adaptation and color match were statistically significant $(\mathrm{p}<0.05)$. It can be concluded that nanofilled resin-modified glass ionomer sealant could be a better alternative to microfilled resin- modified glass ionomer sealant.

Pits and fissure sealants are material that are applied to the pits and fissure surface of teeth to create a thin barrier which protect the surface from decay. Fissure sealant materials fall into two broad categories: Resin-based sealants and glass ionomer sealants. Resinbased sealants are based on acrylic (methacrylate), may or may not contain filler particles or fluoride, and the setting reaction can be automatic (auto-polymerised) or light activated (light-polymerised). Low-viscosity resin-based restorative materials (flowable composites) have also been used as Fissure sealants. $\underline{5}$ Glass ionomer sealants have evolved from glass ionomer cement, which can adhere directly to tooth substance. 6

The glass ionomer cement is water based cement, known as polyalkenoate cement. The generic name is based on the reaction between fluoroaluminosilicate glass and polyalkenonic acid and setting result from an acid/base reaction between the components. 7 These cements are biocompatible, adhesion to moist tooth structure, coefficient of thermal expansion similar to the tooth structure and anticariogenic action due to fluoride release. 8 A new generation of resin-modified (visible light cure) glass ionomer material was introduced acid functional polymer a polycarboxylic acid, water, fluoroaluminosilicate glass as diner and 
base material. The powder liquid ratio was higher than earlier conventional restorative. 9 Improved characteristics include the adhesion, fast setting, ion exchange high level of compressive, flexural and tensile strength, surface hardness high abrasion resistance and fluoride release as well as better sealing abality. $\underline{10}$ However, these, restoratives still have many disadvantages such as a final polishing which can be done only after 24 hours, short working time and slow development of ultimate properties moisture dehydration resulting in microcrack and less cohesive strength as compared to the resin sealant. 11

Recently developed nanofilled glass ionomer restorative material supplied in two parts paste which provides faster, easier, less messy and more reproducible dispensing and mixing com-pared to powder-liquid system. Nanoparticulated ionomer is the first resin-modified glass ionomer cement with nanotechnology, combining the benefits of resinmodified light cure glass ionomer cement and bonded nanofiller particles.12 Nano-technology provides some value added features not typically associated with glass ionomer restorative materials such as improve polish and aesthetics abrasion resistance, strength, optical properties and increased fluoride release. $\underline{13}$ It can be considered that if nanofilled resin-modified glass ionomer sealant can seal the pits and fissure for a longer period with continued fluoride release, a reduction of caries could be expected. However, a few researches have been published whether or not this material is suitable as pit and fissure sealant. Therefore, in the present study, the clinical efficacy of nanofilled resin-modified glass ionomer was compared to that of microfilled resin-modified glass ionomer as pits and fissure sealants in permanent molar teeth.

\section{Materials and Methods}

This prospective comparative study was performed from May 2014 to April 2015.

\section{Study population}

A total of 96 teeth having pits and fissure carious lesion (depth ranged from 1-1.5 $\mathrm{mm}$ ) in permanent molar teeth from 28 patients who visit the outdoor department were selected. They were grouped into two: In Group I, the right sided 48 teeth were restored with nanofilled resin-modified glass ionomer sealant Ketac $^{\mathrm{TM}}$ Nano 100, 3M ESPE, Seefeld, Germany) and in Group II, the left sided 48 teeth were restored with microfilled resin-modified glass ionomer sealant (Hybond Resiglass, Shofu, Kyoto, Japan).

\section{Treatment procedure}

In Group I, the pits and fissure area was cleaned with a slurry of pumice with a bristle brush. Then the tooth was isolated by using cotton rolls. The cavity (diameter: 1 to $1.5 \mathrm{~mm}$ ) was dried and applied primer for $30 \mathrm{sec}$ to prepared semi-dry enamel surface and dried the primer by using air syringe for $30 \mathrm{sec}$ and light cured for $10 \mathrm{sec}$. The sealant material was then applied with an applicator. The sealant was gently teased into the cavity, to avoid entrapping air and it was limited to all pits and fissure but it should not extend onto the unetched surface. The sealant was then light activated for $15 \mathrm{sec}$. After curing the material, the restoration was contoured and polished by using conventional finishing and polishing instruments (Shofu, Japan).

In Group II, the pits and fissure area was cleaned as like Group 1 and then cavity conditioner was applied for $20 \mathrm{sec}$ by using a cotton pellet. They were then rinsed thoroughly with water and dried by gentle blowing with an air syringe. The required amount of cement (one scope of powder with two drops of liquid) was mixed and then fill the cavity by instrument and created the shape desired. Light cured the material by using a dental curing for 20 sec). After 24 hours all the restoration were finished under water cooling with fine and superfine diamond point. Finishing and polishing was done with super snap mini kit (Shofu, Japan).

\section{Clinical assessment}

The patients were recalled for clinical evaluations after 12 months and each restoration was evaluated with dental mirror and probe by two experienced clinicians who were not involved with the study. The restoration was rating according to modified United States Public Health Services (USPHS) criteria. $\underline{14}$ The retention was evaluated by visual inspection with mirror and explorer as alfa (A): Restoration was fully intact, bravo (B): Restoration was partially intact, and charlie (C): Restoration was completely missing. Color match was observed as follows: Alfa (A): Matched the same tooth structure in color, shade and translucency, Bravo (B): Light mismatched in color, shade and translucency between the restoration and treated teeth, Charlie (C): Mismatched in color, shade and translucency outside the acceptable range of the tooth color and translucency. Marginal adaptation between sealant and tooth structure was assessed by visual inspection with mirror and explorer as follows: Alfa (A): Closely adapted, no visual evidence of a crevice along the margin, Bravo (B): Visible crevice along the margin into which the explorer penetrate or catch, Charlie (C): Visible evidence of a crevice along the margin into which the explorer penetrate or catch. The dentin or the base was exposed.

\section{Statistical analysis}

Data of retention, color match and marginal adaptation were recorded in the data collection 
sheet individually. Statistical analysis of the results was done by using computer based statistical software, SPSS 20.00 Version (SPSS Inc. Chicago, USA). For significance of difference Chi-square test was performed; $\mathrm{p}$ value $<0.05$ was considered as statistically significant.

\section{Results}

The results of clinical assessment at 12 months are shown in Table I and Figure 1. It was found that at the end of 12 months, 5 cases of Group I and 12 cases of Group II were not evaluated because these patients were absent at this period. Among the remaining samples, 40 restorations of Group I was fully intact. The remaining 3 restorations were completely missing from the cavity. On the other hand, in Group II, 29 teeth were intact and the

\begin{tabular}{|c|c|c|c|c|}
\hline \multicolumn{5}{|c|}{ Table I } \\
\hline \multicolumn{5}{|c|}{ Comparison of clinical results between two groups at 12 months } \\
\hline Evaluation criteria & Score & $\begin{array}{l}\text { Group I } \\
(\mathrm{n}=43)\end{array}$ & $\begin{array}{c}\text { Group II } \\
(\mathrm{n}=36)\end{array}$ & $\mathrm{p}$ value \\
\hline \multirow[t]{3}{*}{ Retention } & Alpha & 40 & 29 & \multirow[t]{3}{*}{0.145} \\
\hline & Bravo & 0 & 0 & \\
\hline & Charlie & 3 & 7 & \\
\hline \multirow[t]{3}{*}{ Color match } & Alpha & 37 & 23 & \multirow[t]{3}{*}{0.008} \\
\hline & Bravo & 6 & 6 & \\
\hline & Charlie & 0 & 7 & \\
\hline \multirow[t]{4}{*}{ Marginal adaptation } & Alpha & 37 & 21 & \multirow[t]{4}{*}{0.002} \\
\hline & Bravo & 6 & 6 & \\
\hline & Charlie & 0 & 9 & \\
\hline & Missing cases & 5 & 12 & \\
\hline
\end{tabular}

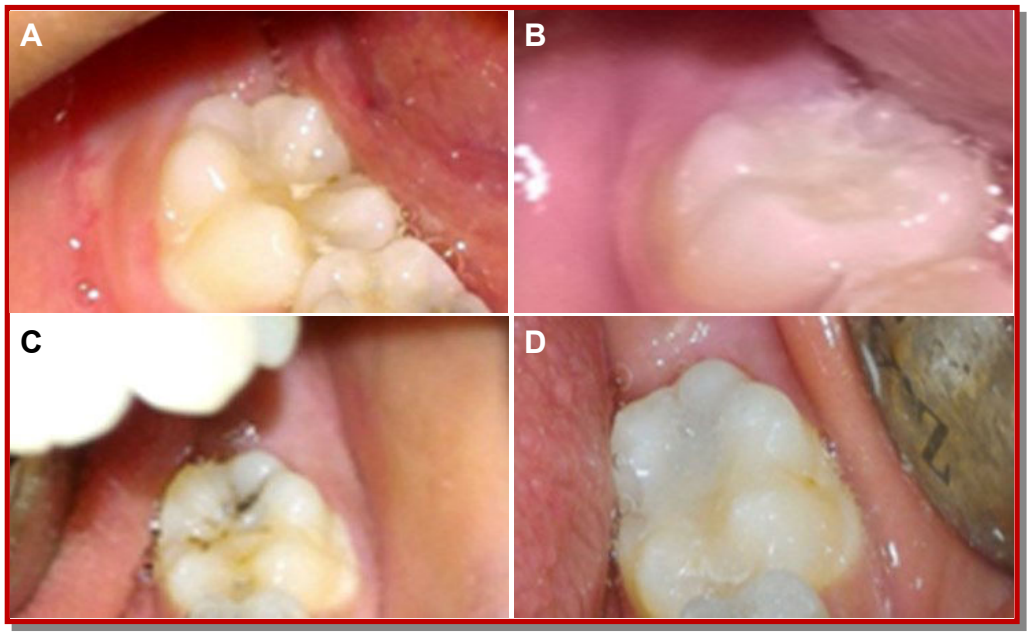

Figure 1: Representative photographs of pit and fissures sealed by nanofilled (Upper row) and microfilled rein-modified (lower row) glass ionomer sealant. $(A, C)$ Preoperative view of fissure caries, (B,D) At 12 months following application remaining 7 restorations were completely missing from the cavity. Regarding color matching, 37 restoration in Group I and 23 in Group II showed alpha rating. The remaining restoration was slightly mismatched in color with the same teeth. On marginal adaptation, 37 restoration in Group I and 21 of Group II had no visual crevice along the margin and explorer did not catch at the end of 12 months. There was statistically significant difference between nanofilled and microfilled resinmodified glass ionomer sealant on color matching and marginal adaptation at 12 months.

\section{Discussion}

Previous studies have indicated that excellent retention and longevity of sealants depend on the degree of remaining debris, the penetrability of the sealant material into acid-etched enamel or marginal sealing, and wear or abrasion resistance. $.15,16$ The results of sealant retention, marginal adaptation and color matches in the present study corresponded to a previous study. 12 When sealant restoration was examined at 12 months, it was found that nanofilled sealant restoration showed acceptable retention, color matches as well as excellent marginal adaptation with the treated teeth. Nanoparticulated ionomer is resin-modified glass ionomer cement with nanotechology, which combines the benefits of resin modified glass ionomer and bonded nanofiller particles. 17 The broad range of filler particle could influence the strength, optical properties, and abrasion resistance. The development of nanotechnology has become the most highly energized disciple science and technology.17 So, the benefits from these two technologies are glass ionomer with improved polish, adhesion, and aesthetics. It also has improved abrasion resistance, strength optical properties, as well as increased fluoride release. In addition, there is also less number of void, cracks a micro-porosities on the surface in nano-ionomer than the other ionomer available study. $\underline{12}$

The results of sealant retention revealed that 40 cases of Ketac ${ }^{\mathrm{TM}}$ Nano 100 and 29 cases of Hy-bond Resiglass showed alpha rating. However, 3 cases of nano-filled and 7 cases of microfilled resin-modified glass ionomer sealant restorations were completely lost. The loss of retention may be due to moisture contamination, followed by a second loss associated with material wear under forces of occlusion. 18 Loss of sealant could also be due to inadequate adhesion of the cement with enamel surface, $\underline{\underline{19}}$ or loss of adhesion between sealant material with the tooth tissue or insufficient penetration of the sealant into the cavity. $\underline{20}$ There may also be residual debris or entrapped air when placing the sealant into the cavity. Therefore, it can be assumed that debris remaining after fissure cleaning by pumice with 
bristle brush may inhibit penetration of primer into the enamel surface. Some previous studies have reported that adequate cleaning of pits and fissures prior to primer application is essential for the success of fissure sealant retention. 21,22 Persistence of debris, entrapped air and presence of unetched are also responsible for early sealant loss, which may be the possible reason of loss of restoration in 3 cases of $\mathrm{Ketac}^{\mathrm{TM}} 100$ and 7 cases of Hy-bond Resiglass at 12 months.

Regarding the color match, the present study revealed that 37 restorations in Group I and 23 in Group II remained alpha rating at 12 months. Furthermore, the difference between Ketac ${ }^{\mathrm{TM}} \mathrm{Nano}$ 100 and Hy-bond Resiglass was statistically significant. Previous studies have reported the mismatching of color may be due to either difference of filler particles or it can occur due to body discoloration of the monomer. $\underline{23}$ It has been reported that the particle size of Ketac ${ }^{\mathrm{TM}}$ Nano 100 ranged from 5 to $25 \mathrm{~nm}$ or $0.1 \mathrm{~nm}$, which is far below the wavelength of light, marking them immeasurable by the refractive index. When the light comes in, it passes directly through the materials, making it highly translucent. In addition, the nanoparticles preferentially scatter blue light, giving the restoration opalescent effects. 16 On the other hand, the particle size of microfilled resinmodified glass ionomer is ranged from 4.5 to 4.8 micrometers. $\underline{24}$ Low filler particles containing material is said to have good polishability as well as stability of the color. Chemical reaction of the resinmatrix, water absorption and the surface characteristics of the set material can be responsible for the alteration in color matches with the natural teeth. Another study reported that the change of color may be due to body discoloration of monomer matrix. $\underline{23}$ This might be the possible reason of loss of color in Hy-bond Resiglass sealant.

On marginal adaptation, the results showed that nanofilled resin-modified glass ionomer revealed better marginal adaptation than that of microfilled resin-modified glass ionomer. At 12 months, the result between the two groups was statistically significant $(p<0.05)$. However, 6 cases of nanofilled showed Bravo rating at 12 months. On the other hand, 6 cases of microfilled resin-modified glass ionomer sealant revealed bravo and 9 cases showed Charle rating. Careful observation of these restorations showed that restorations, where adaptation lost, were due to chipping at the enamel margin. This might be possible reason for loss of marginal retention in the present study. Chipping of enamel surface can occur due to direct contact with the opposite tooth cusp or may be due to thin enamel surface. Another possible reason might be the flow of the materials. The previous study has reported that the follow of nanofilled ionomer sets by instant resin polymerization, and once irradiated, they do not require protection from moisture contamination hence resulting in better marginal adaptation. $\underline{24}$ The other reason could be the use of Ketac ${ }^{\mathrm{TM}}$ Nano primer helps in increasing adhesion with the tooth tissue and increased water uptake and expansion of cement the better sealing of material.24 Other possible reasons for the loss of marginal adaptation are entrapped air or voids during filling of the cavity as reported by a previous study. .20

\section{Conclusion}

The result of one year observation confirmed that nanofilled resin-modified glass ionomer is a better alternative to microfilled resin-modified glass ionomer sealant.

\section{Ethical Issue}

The research protocol was approved by the committee and permission for the study was taken from the Institutional Review Board of Bangaban-dhu Sheikh Mujib Medical University.

\section{Acknowledgement}

This work was supported by the Research Grant for Student, Bangabandhu Sheikh Mujib Medical University.

\section{References}

1. Petersen PE. Global policy for improvement of oral health in the 21st century-implications to oral health research of World Health Assembly 2007, World Health Organization Community. Dent Oral Epidemiol. 2009; 37: 1-8.

2. Whelton H, Crowley E, O'Mullane D, Donaldson M, Cronin M, Kelleher V. Dental caries and enamel fluorosis among the fluoridated population in the republic of Ireland and non-fluoridated population in Northern Ireland in 2002 Community Dent Health. 2006; 23: 37-43.

3. Elfrink ME, Veerkamp JS, Kalsbeek H. Caries pattern in primary molars in Dutch 5-year-old children. Eur Arch Paediatr Dent. 2006; 7: 236-40.

4. Slade GD, Spencer AJ, Davies MJ, Burrow D. Intra -oral distribution and impact of caries experience among South Australian School Children. Aust Dent J. 1996; 41: 343-50.

5. Kucukyilmaz E, Savas S. Evaluation of different Fissure sealant materials and flowable composites used as Pit and Fissure sealants: A 24 months clinical trial. Pediatr Dent. 2015; 37: 468-73.

6. Van Meerbeek B, De Munck J, Yoshida Y, Inoue S, Vargas M, Vijay P, Van Landuyt K, Lambrechts P, Vanherle G. Buonocore memorial lecture. Adhe- 
sion to enamel and dentin: Current status and future challenges. Oper Dent. 2003; 28: 215-35.

7. Karantakis $\mathrm{P}$, Helvatjoglou-Antoniades $\mathrm{M}$, Theodoridou-Pahini S, Papadogiannis Y. Fluoride release from three glass ionomers, a compomer and a composite resin in water, artificial saliva and lactic acid. Oper Dent. 2000; 25: 20-25.

8. Kent BE, Lewis BG, Wilson AD. Glass ionomer cement formulations: I. The preparation of novel fluoroaluminosilicate glasses high in fluorine. J Dent Res. 1979; 58: 1607-19.

9. Yilmaz Y, Eyuboglu O, Kocogullari ME, Belduz N A one-year clinical evaluation of high-viscosity glass ionomer cement in primary molars. J Contemp Dent Pact. 2006; 7: 71-78.

10. Malek S, Hossain M, Gafur M, Rana M, Moral M. Comparative study of resin sealant and resin modified glass ionomer as pit and fissure sealant. Bangabandhu Sheikh Mujib Med Univ J. 2017; 10: 21-26.

11. Anusavice KJ. Informatics systems to assess and apply clinical research on dental restorative materials. Adv Dent Res. 2003; 17: 43-48.

12. Pachoal MA, Magalhaes Ac, Rios D, Abdo RC, Gurgel CV, Chaves JV. Fluoride release of a nanoparticulated resin-modified glass ionomer cement. Oral health and preventive dentistry. $86^{\text {th }}$ General Session and Exhibition of the IADR, 2008. Toronoto, Annals of the LADR, 2008, pp 61-5.

13. Markovic DL, Petrovik BB, Peric TO. Fluoride content and recharge ability of five glasses ionomer dental materials. BMC Oral Health. 2008; 8: $1-21$.

14. Gallo JR, Burgess JO, Ripps AH, Walker RS, Maltezos MB, Mercante DE, Devidson JM. Thee years clinical evaluation of two flowable composites. Quint Int. 2010; 41: 497-503.

15. Futatsuki M, Kubota K, Yeh YC, Park K, Moss SJ.
Early loss of pit and fissure sealant: A clinical and SEM study. J Clin Pediatr Dent. 1995; 19: 99-104.

16. Burrow JF, Burrow MF, Makinson OF. Pits and fissures: Relative space contribution in fissures from sealants, prophylaxis pastes and organic remnants. Aust Dent J. 2003; 48: 175-79.

17. Mitra SB, Doing WU, Holmes BN. An appliation of nanotechnology in advanced dental materials. J Am Dent Assoc. 2003; 134: 1382-90.

18. Messer LB, Calache H, Morgan MV. The retention of pit and fissure sealants placed in primary school children by Dental Health Services, Victoria. Aust Dent J. 1997; 42: 233-39.

19. Mejare I, Major IA. Glass ionomer and resin-based fissure selants: A clinical study. Scand J Dent Res. 1990; 98: 345-50.

20. Yamada $Y$, Hossain M, Shimizu Y, Kimura Y, Masuda Y, Nakamura Y, Matsumoto K. Analysis of surface roughness and microleakage of fissure sealants following organic debris removal with Carisolv. J Dent. 2008; 36: 130-37.

21. Duangthip D, Lussi A. Effects of application techniques and fissure types on the in vitro performance of two fissure sealants. Am J Dent. 2004; 17: 137-42.

22. Srinivasan V, Deery $C$, Nugent $Z$. In vitro microleakage of repaired Fissure sealants: A randomized, controlled trial. Int J Pediatr Dent. 2005; 15: 51-60.

23. Konde S, Raj S, Jaiswal D. Clinical evaluation of a new art material: Nanoparticulated resin-modified glass ionomer cement. J Int Soc Prev Community Dent. 2012; 2: 42-47.

24. Van Dijken JW, Horstedt P. Marginal adapation to enamel of a polyacid-modified resin composite (compomer) and a resin-modified glass ionomer cement in vivo. Clin Oral Invest. 1997; 1: 185-90. 